Intravenous

\section{azithromycin as salvage therapy in a patient with Legionnaire's disease}

\author{
L Dorrell, B Fulton, E L C Ong
}

\begin{abstract}
A patient with proven Legionnaire's disease is described whose clinical condition improved with intravenous azithromycin after failure to respond to treatment with erythromycin and rifampicin.
\end{abstract}

(Thorax 1994;49:620-621)

Infection with Legionella pneumophila is a relatively uncommon cause of pneumonia in adults, accounting for $2-6 \%$ of cases acquired in the community in the United Kingdom. ${ }^{1}$ Erythromycin has been the agent of choice in the treatment of Legionella pneumonia, but therapeutic failures have been documented ${ }^{2}$ and antibiotic resistance due to emergence of mutant strains has been demonstrated in vitro. ${ }^{3}$ Recently, macrolides such as azithromycin have been shown to have superior activity against $L$ pneumophila in an animal model of Legionnaire's disease. ${ }^{4}$

We report a case of Legionnaire's disease where intravenous azithromycin was used as salvage therapy in a patient who had not responded to treatment with erythromycin and rifampicin.

\section{Case report}

A 38 year old man presented to his general practitioner with a five day history of headache, abdominal pain, and offensive urine following a holiday in France during which he stayed in a hotel. He was treated with cotrimoxazole and subsequently developed a dry cough and exertional dyspnoea.

On admission he was febrile with a temperature of $38.6^{\circ} \mathrm{C}$ and had signs of consolidation in his right lung. He was treated for suspected pneumonia and pyelonephritis with intravenous Augmentin. The chest radiograph on admission showed extensive consolidation in both lung fields. Biochemical investigations showed a serum sodium concentration of $125 \mathrm{mmol} / 1$.

On the third day, despite initiation of continuous positive airway pressure (table 1) he continued to deteriorate and needed to be intubated and was supported with intermittent positive pressure ventilation and positive end expiratory pressure of $10-15 \mathrm{~cm} \mathrm{H}_{2} \mathrm{O}$ (fig 1 ). As Legionnaire's disease was suspected his antimicrobial treatment was therefore changed to intravenous erythromycin, $1 \mathrm{~g}$ six hourly, and cefotaxime, $1 \mathrm{~g}$ eight hourly. Legionella serogroup 1 antigen was detected in his urine by enzyme linked immunosorbent assay three days later.

Over the following three days he deteriorated so intravenous rifampicin $300 \mathrm{mg}$ daily was added. Total parenteral nutrition was commenced in view of his catabolic state. An elective tracheostomy was performed.

Ten days after admission his renal function deteriorated, his serum creatinine rising to $129 \mu \mathrm{mol} / 1$ and urea to $12.5 \mathrm{mmol} / \mathrm{l}$. Urine biochemical analysis was compatible with established renal failure: urine sodium was $309 \mathrm{mmol} / 24$ hours (normal range 100$250 \mathrm{mmol} / 24$ hours) and urine potassium was within the normal range at $94 \mathrm{mmol} / 24$ hours. In addition, proteinuria of $2 \mathrm{~g}$ in 24 hours was observed. There was no evidence of a disseminated intravascular coagulopathy.

Pulmonary artery flotation catheter studies showed that the pulmonary artery pressure was $64 / 34 \mathrm{~mm} \mathrm{Hg}$ (normal range 15-30/ 3-15 $\mathrm{mm} \mathrm{Hg}$ ) and pulmonary capillary wedge pressure was $17 \mathrm{~mm} \mathrm{Hg}$ (normal range 6$12 \mathrm{~mm} \mathrm{Hg}$ ); cardiac output was $181 / \mathrm{min}$ (nor$\mathrm{mal} 5-5.5 \mathrm{l} / \mathrm{min}$ ) and systemic vascular resistance was 408 dynes $\mathrm{s} \mathrm{cm}^{-5}$ (normal range 900-1200). The elevated pulmonary capillary pressure was attributed to fluid overload and the raised cardiac output, together with a low systemic vascular resistance, were compatible with his sepsis syndrome. Continuous arteriovenous haemofiltration was therefore commenced.

The patient's clinical condition deteriorated further and treatment with intravenous azithromycin was initiated (fig 2). The patient received a dose of $250 \mathrm{mg}$ 12-hourly on the first day followed by a dose of $250 \mathrm{mg}$ once daily for 13 days. After 48 hours of treatment both clinical and radiological improvement were observed (table 1). Erythromycin and rifampicin were discontinued after the first 24 hours of azithromycin therapy.

The patient's renal failure worsened with his serum creatinine stabilising at around $500 \mu \mathrm{mol} / 1$. Continuous arteriovenous haemodiafiltration was commenced. It is not clear whether azithromycin may have contributed to the impairment of his renal function.

Three weeks after admission the serological tests became positive for Legionella, with a

\begin{tabular}{|c|c|c|c|c|}
\hline $\begin{array}{l}\text { Days after } \\
\text { admission }\end{array}$ & $\mathrm{FIO}_{2}$ & $\begin{array}{l}\mathrm{PaO}_{2} \\
(\mathrm{kPa})\end{array}$ & $\begin{array}{l}\mathrm{PaCO}_{2} \\
(\mathrm{kPa})\end{array}$ & $p H$ \\
\hline 2 & $\begin{array}{l}0.3 \\
0.5\end{array}$ & $\begin{array}{l}5.3 \\
5.8\end{array}$ & $\begin{array}{l}4 \cdot 5 \\
4 \cdot 8\end{array}$ & $\begin{array}{l}7.52 \\
-\end{array}$ \\
\hline 3 & \multicolumn{4}{|c|}{ IPPV started } \\
\hline 6 & 0.7 & $19 \cdot 9$ & - & $\overline{7}$ \\
\hline 12 & 0.6 & 8.9 & 5.9 & 7.32 \\
\hline 18 & \multicolumn{4}{|c|}{$\begin{array}{l}0.6 \\
\text { Azithromycin started }\end{array}$} \\
\hline 20 & & $\begin{array}{ll}11.8 & 5 \\
15.5 & 4\end{array}$ & $\begin{array}{l}5.9 \\
4.7\end{array}$ & $\begin{array}{l}7.35 \\
7.4\end{array}$ \\
\hline 26 & \multicolumn{4}{|c|}{$\begin{array}{l}0.35 \quad 15 \cdot 3 \\
\text { Artificial ventilation stopped }\end{array}$} \\
\hline
\end{tabular}

$\mathrm{FIO}_{2}=$ fractional inspired oxygen; $\mathrm{PaCO}_{2}=$ arterial oxygen tension; $\mathrm{PacO}_{2}=$ arterial carbon dioxide tension; IPPV = intermittent positive pressure ventilation. 


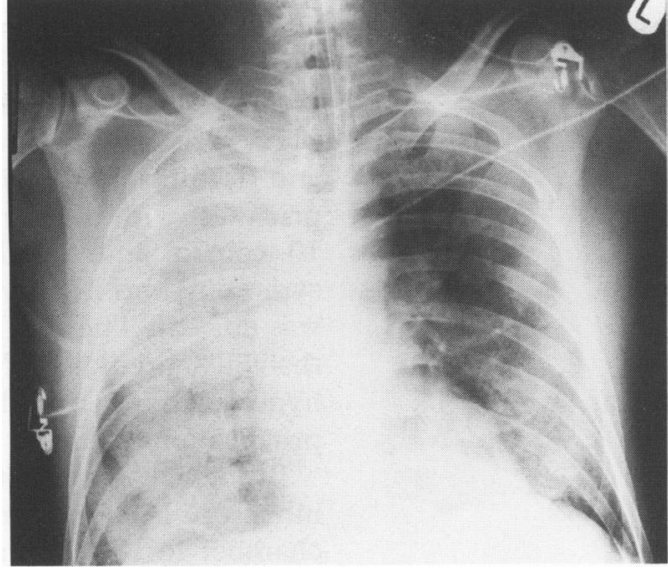

Figure 1 Chest radiograph showing extensive consolidation on the third day when intubation and ventilation was started.

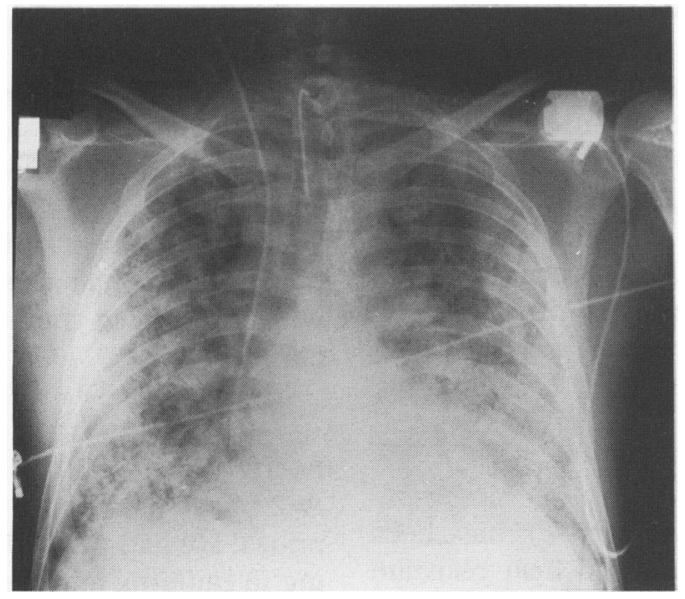

Figure 2 Chest radiograph taken before azithromycin treatment.

titre of $1 / 512$ to serogroup 1 compared with a baseline value of $<1 / 16$. Titres to serogroup 6 rose to $1 / 256$.

The patient's clinical condition continued to improve. He required haemodialysis for a further week and was discharged five weeks later, since when he has remained well with normal renal function and a normal chest radiograph.

\section{Discussion}

We describe a patient with proven severe Legionella pneumonia whose clinical condition improved with intravenous azithromycin. Azithromycin differs structurally from the macrolide erythromycin by the insertion of a methyl substituted nitrogen at position $9 \mathrm{a}$ in the lactone ring creating a 15 numbered structure. This modification leads to an extension of the broad spectrum of activity against Gram positive and Gram negative bacteria. ${ }^{5}$ Azithromycin achieves high concentration in different tissues, including lungs, and these concentrations are in excess of the minimal inhibition concentrations against various microorganisms including $L$ pneumophila ${ }^{6}$ and therefore may explain the improvement in our patient's condition. Quinolones such as ciprofloxacin have also been shown to have activity against $L$ pneumophila. ${ }^{?}$

A definitive diagnosis of Legionnaire's disease may be difficult to establish early in clinical practice as culture of the organism requires the use of multiple selective media and the sensitivity of this method is variable. Direct fluorescent antibody staining of sputum or bronchoalveolar lavage fluid is highly specific and provides a rapid diagnosis but also has a relatively low sensitivity. Detection of soluble $L$ pneumophila antigen in urine by enzyme linked immunosorbent assay overcomes some of the difficulties inherent in these methods; positive results can be obtained within three days of the onset of symptoms as illustrated in our case and this method has a sensitivity of $80 \% .^{8}$

Azithromycin has been shown to be as effective as erythromycin and better tolerated in the treatment of atypical pneumonia in adults. ${ }^{9} \mathrm{~A}$ three day regimen of azithromycin was shown in a single blind study to be as effective clinically and microbiologically as a 10 day regimen of co-amoxiclav in the treatment of acute lower respiratory tract infections. ${ }^{10}$

As far as we are aware, this is the first case report where intravenous azithromycin has been used in the treatment of a patient with severe legionellosis. Clinicians should consider this option for critically ill patients in whom standard treatment has failed.

We are grateful to Dr M Hodges, Pfizer Central Research, Sandwich, for supplying azithromycin; Dr J Williams, West Cumberland Hospital, Whitehaven, for referring the patient; and $\operatorname{Dr} M$ Ward, Royal Victoria Infirmary, Newcastle upon Tyne for management of the patient's renal failure.

1 Research Committee of the British Thoracic Society and Public Health Laboratory Service. Community-acquired pneumonia in adults in British hospitals in 1982-1983. Q f Med 1987;239:195-220.

2 Mercatello A, Frappaz D, Robert D. Failure of erythromycin/rifampicin treatment of Legionella pneumophila. F Infect 1985;10:282-3.

3 Moffie BG, Mouton RP. Sensitivity and resistance of Legionella pneumophila to some antibiotics and combinations of antibiotics. $\mathcal{F}$ Antimicrob Chemother 1988;22:457-62.

4 Fitzgeorge RB, Featherstone ASR, Baskerville A. Efficacy of azithromycin in the treatment of guinea pigs infected of azithromycin in the treatment of guinea pigs infected with Legionella pneumophila by ae

5 Retsema JA, Girard A, Shelkley W, Manousos M, Anderson $M$, Bright $G$, et al. Spectrum and mode of action of azithromycin (CP-62 993), a new 15-membered-ring macrolide with improved potency against Gram-negative organisms. Antimicrob Agents Chemother 1987;31:193947.

6 Foulds G, Shepard RM, Johnson RB. The pharmacokinetics of azithromycin in human serum and tissues. $\gamma$ Antimicrob Chemother 1990;25(Suppl A):73-82.

7 Unertl K, Lenhaut FP, Forst H, Vogler G, Wilm G, Ehret W, et al. Brief report: ciprofloxacin in the treatment of legionellosis in critically ill patients including those cases unresponsive to erythromycin. Am $\mathcal{F}$ Med 1987; Suppl $5 \mathrm{~A}: 128-31$.

8 Zuravleff JJ, Yu VL, Shonnard J. Diagnosis of Legionnaire's disease: an update of laboratory methods with new emphasis on isolation by culture. $7 A M A$ 1983;250:1981-5.

9 Schonwald S, Gunjaca M, Kolacny-Babic L, Cav V, Gosev $M$. Comparison of azithromycin and erythromycin in the treatment of atypical pneumonias $f$ Antimicrob Chemother 1990;25(Suppl A):123-6.

10 Haepelman AIM, Sips AP, Van Helmond JLM, Van Barneveld PWC, Neve AJ, Zwinkels M, et al. A single Barneveld PWC, Neve AJ, Zwinkels $M$, et al. A single blind comparison of 3 day azithromycin and 10 day cotions. F Antimicrob Chemother 1993;31(Suppl E):147-52. 